\title{
El gobierno metropolitano como gobernabilidad: entre la autorregulación y la orientación política ${ }^{1}$
}

\section{Metropolitan government as governance: between self-regulation and political orientation}

Pedro Pírez*

\begin{abstract}
This paper presents an approach to study the local urban government. It reviews the arguments of governability-governance, like a proposal of a method or instrument of government, which limits the ability to perceive the role of the State and the situations of concentration of power. It proposes to introduce the notion of orientation of social and territorial processes from the political-bureaucratic apparatuses. It refers to the Metropolitan Area of Buenos Aires, identifying an inter-jurisdictional structure characterized by the dominance of the federal government, studying the processes and policies that were part of the neoliberal restructuring over the 1990's.
\end{abstract}

Keywords: governability, governance, orientation, neoliberalism, metropolitan area, Buenos Aires.

\begin{abstract}
Resumen
Esta investigación presenta una perspectiva para estudiar al gobierno urbano local. Analiza la argumentación de la gobernabilidad-governance, entendida como la propuesta de un método o instrumento de gobierno que limita la capacidad de percibir el papel del Estado y las situaciones de concentración de poder. Propone introducir la noción de orientación de los procesos sociales y territoriales desde los aparatos político-burocráticos; se refiere al Área Metropolitana de Buenos Aires, identificando una estructura interjurisdiccional caracterizada por el predominio del gobierno federal, estudiando los procesos que hicieron parte de la reestructuración neoliberal durante los años noventa.
\end{abstract}

Palabras claves: gobernabilidad, governance, orientación, neoliberalismo, área metropolitana, Buenos Aires.

* Universidad de Buenos Aires. Correo-e: ptpirez@gmail.com

${ }^{1}$ Una versión anterior de este artículo fue preparada para el V Congreso Latinoamericano de Ciencia Política (Buenos Aires, julio de 2010) y es parte de los trabajos realizados dentro del Programa de Investigación Plurianual (PIP), núm. 1810, apoyado por el Consejo Nacional de Investigaciones Científicas y Técnicas (Conicet). Agradezco los comentarios de Guillermo Jajamovich y de la evaluación anónima. 


\section{Introducción}

Esta investigación se basa en reflexiones surgidas en los estudios que hemos llevado a cabo sobre la situación metropolitana de Buenos Aires. En ellas intentamos superar las proposiciones normativas para desarrollar trabajos analíticos que permitieran el conocimiento de los procesos políticos reales que afectan sus dimensiones económica, social y territorial.

En esa tarea dejamos de lado los intentos de fundamentar posibles organizaciones metropolitanas de gobierno y gestión para tratar de comprender el funcionamiento político de esa realidad para poder entender, entre otros aspectos, la persistente ausencia de configuraciones políticoinstitucionales de nivel metropolitano, por una parte, y el funcionamiento urbano-metropolitano, por la otra.

Con esos objetivos, buscamos apoyo en enfoques teóricos que, desde perspectivas políticas, plantearan la cuestión del gobierno de la ciudad, poniendo en operación algunos argumentos más generales. No encontramos en los estudios latinoamericanos antecedentes que permitieran sustentar conceptualmente esa mirada y recurrimos a algunos enfoques anglosajones. En particular, enfoques de gobernabilidad y su aplicación en tanto governance (Pírez, 2007).

La investigación se apoyó en el análisis de las relaciones políticas en el territorio metropolitano y, particularmente, en el papel que desempeñan los diferentes aparatos gubernamentales allí presentes. Ese intento permitió identificar una situación particular que se configura en las relaciones interjurisdiccionales en la que aparece con un papel predominante el gobierno federal.

Al mismo tiempo, fue posible percibir algunas debilidades de los enfoques teóricos; buscando la manera de superarlas realizamos una reflexión sobre la perspectiva de gobernabilidad-governance. El estudio de las relaciones políticas en el Área Metropolitana de Buenos Aires y, particularmente, de la presencia de los niveles federal, provincial y municipal y sus relaciones, sustentó una lectura crítica que aquí se presenta.

Este artículo es consecuencia de los trabajos mencionados y ofrece, de manera breve, una reflexión sobre las dificultades o debilidades analíticas que encontramos en los enfoques de governance y la manera en que, introduciendo la noción de orientación, intentamos superarlas en el estudio de la situación metropolitana de Buenos Aires.

Para ello exponemos de manera sucinta una crítica a los enfoques de governance como resultado de las relaciones de redes autorreguladas (2.1.), y la noción de orientación como resultado de relaciones de poder (2.2.). Seguidamente presentamos, también de manera breve, un análisis de la orientación metropolitana en Buenos Aires, puntualizando en el aparato 
político-burocrático (3.1.), en las relaciones políticas (3.2.), y en su concreción en procesos metropolitanos ocurridos como parte de la reestructuración neoliberal (3.3.).

\section{Gobierno como orientación}

\subsection{Colaboración o poder}

Comencemos suponiendo que gobernar implica, además de la posibilidad de ordenar y ser obedecido, la aceptación social de esa actividad en razón tanto de su adecuación con la formalidad como con valoraciones. ${ }^{2}$

$\mathrm{Al}$ mismo tiempo, el gobierno (desde donde se ejerce esa actividad de gobernar) es un aparato político-burocrático: autoridad política superior en un territorio dado que ordena la vida política, económica y cultural; distribuye y redistribuye bienes económicos y otros privilegios; se hace cargo de las cuestiones públicas que no pueden subordinarse a los particulares; y es aceptado (obedecido) por la población (Arbós y Giner, 1993).

Esa perspectiva justifica la relevancia de identificar dificultades o limitaciones de ese aparato que pueden entenderse como condiciones de ingobernabilidad, ${ }^{3}$ particularmente si se las compara con "la eficacia que resulta de las decisiones tomadas por los grupos sociales" (Arbós y Giner, 1993: 8).

En ese contexto, la gobernabilidad, condición del gobierno, es entendida como la capacidad de superar sus limitaciones, particularmente aquéllas asociadas con la dimensión político-burocrática. Al pensar esa situación en comparación con la eficacia de los grupos sociales, se apunta a definir al gobierno con referencia en las relaciones que esos grupos establecen en sus comportamientos; de allí la derivación a la noción de governance y a la idea de una realidad conformada por redes, que, en tal

\footnotetext{
${ }^{2}$ El origen weberiano de esta distinción es claro; por otra parte, podemos considerar que la legitimidad está consecuentemente asociada a la redistribución equitativa de los bienes sociales o, por el contrario, a la libertad de las relaciones económicas (Arbós y Giner, 1993). Esta dimensión podría enriquecerse incorporando la distinción que trabaja Landau sobre legitimidad y confianza (Landau, 2008).

${ }^{3}$ Recurrimos a la noción inicial de gobernabilidad entendiendo las dificultades de los aparatos gubernamentales para responder a las cuestiones que le plantea la sociedad. No es necesario aceptar el sesgo ideológico de la formulación inicial de la Trilateral (Crozier et al., 1975), según la cual las demandas democráticas sobrepasan a las capacidades de respuesta, para entender la dificultad o incapacidad del gobierno para enfrentar situaciones problematizadas por una política en particular. Es posible pensar la gobernabilidad, o su contraria la ingobernabilidad, por ejemplo, en referencia al desarrollo de políticas diferentes y, más aún, contrarias a los intereses más poderosos de una sociedad o de una ciudad.
} 
sentido, permiten superar la noción burocrático-política de gobiernogobernar sin gobierno, como dice Rhodes. ${ }^{4}$

Por detrás de esta concepción está la idea de la colaboración (sociedad civil-Estado/grupos sociales-aparato político-burocrático) como medio de superar las limitaciones mencionadas. Más aún, según el autor citado, "El Estado se convierte en un conjunto de redes entre organizaciones formadas por actores gubernamentales y sociales sin un actor soberano capaz de dirigir o regular" (Rhodes, 1996: 666) (la traducción es mía).

La cuestión de la gobernabilidad comenzó como una preocupación por las limitaciones gubernamentales, pero su recorrido parece llegar a suponer que las limitaciones que se intenta superar son aquellas que provienen de las diferencias, oposiciones o contradicciones con los intereses sociales propios de los grupos de poder y sus correspondencias dentro de los aparatos gubernamentales.

En tal sentido, el sesgo autorregulador (opuesto tanto a las relaciones de mercado como a las relaciones de jerarquía gubernamental) sugiere autonomía. Sin embargo, la sociedad se caracteriza por la existencia de diferentes y desiguales relaciones de heteronomía.

En consecuencia, la visión de autorregulación de redes implica desconocer que la sociedad (y así el sistema de relaciones y de redes) se estructura con base en una distribución desigual del poder y, particularmente, de la concentración de éste (dentro y entre las redes). Al mismo tiempo, la visión de redes autorreguladas niega la relevancia de los aparatos estatales y su vínculo particular con las relaciones desiguales y concentradas de poder en la sociedad. De allí que la colaboración aparezca como el rasgo principal que explica las decisiones políticas.

Esta manera de mirar la realidad dificulta percibir los elementos sustantivos de las relaciones políticas y se basa en el supuesto (implícito) de una dispersión del poder, de ausencia de procesos de concentración de éste y de capacidades diferenciales de incidencia en las decisiones estatales. La observación de la realidad muestra un panorama muy diferente. En efecto, en los últimos treinta años se percibe un claro proceso de concentración de poder, tanto en términos internacionales como dentro de los límites territoriales de los países.

Al mismo tiempo, los aparatos estatales mantienen un papel central en la definición de los parámetros de los comportamientos privados. Basta indicar que el desarrollo de las nuevas relaciones, dentro de lo que se ha denominado la globalización, se ha sustentado en la existencia de

\footnotetext{
${ }^{4}$ Podemos considerar como punto de partida la distinción que propone Rhodes entre "estructuras de gobierno" como son la jerarquía (como en la burocracia y la coordinación por órdenes administrativas), el mercado (con la privatización, las pruebas de mercado o competencia de precios) y las redes con ajustes mutuos (governance) (Rhodes, 1996: 653) (La traducción es mía).
} 
reformas normativas (regulaciones): desde las llamadas desregulaciones hasta llegar a los procesos de privatización, tanto por transferencia de activos o de capacidades de toma de decisión como, aun sin esos cambios, por la reorientación hacia condiciones mercantiles de los procesos previamente desmercantilizados como es el caso de algunos servicios de infraestructura (Pírez, 2011).

Por otra parte, y de alguna manera en coherencia con lo anterior, es posible percibir que la argumentación propia de governance se refiere "principalmente con el método, con la práctica dirigida a una mejor cooperación entre los protagonistas de la escena urbana” (Jouve y Lefèvre, 2004: 9). En suma, se trata particularmente de los medios para lograr el buen gobierno, la buena governance.

Esto es, repetimos, la mejor cooperación entre los actores sociales comprometidos. Surge inmediatamente la duda acerca de si esa posible mejor cooperación no depende de los fines para los cuales se organiza y, en tal sentido, podrían encontrarse diferentes combinaciones de actores y distintas configuraciones. Es difícil pensar ese caso dentro de los marcos de la autorregulación de las redes porque deberá ser resuelto no por cooperación (autorregulación) sino por ejercicio de poder, normalmente de autoridad.

Esa dificultad no se reconoce en el discurso que analizamos, no solamente porque en su argumentación las situaciones de poder se desvanecen, sino también porque la cuestión en juego es entendida como un asunto de método que apunta a los procedimientos, dejando, predominantemente, los fines fuera del foco de atención.

Se deja de lado qué se propone realizar, atendiendo a cómo hacerlo. Es decir, no se cuestiona la significación del contenido del gobierno. No es un problema qué hacer desde el gobierno (en este caso, qué hacer con la ciudad). Cuando decimos que no se cuestiona estamos significando que no se lo considera como una cuestión.

Podemos inferir que se deja fuera la controversia sobre el qué. Sin embargo, es posible reconocer que, en general, en esas propuestas de método, de camino, viene implícita la meta. ${ }^{5}$ Puede pensarse en particular en la imposición de un modelo de ciudad que se toma como dado, aquello que ha sido llamado "a cidade do pensamento único" (Arantes et al., 2000).

Es posible vincular este aspecto con la conceptualización de J. Davies de la governance como hegemonía (Davies, 2011), dado que esas metas son el resultado de decisiones (expresas o no) basadas en relaciones de poder y transmitidas, tendiendo a su naturalización por diversos medios.

\footnotetext{
${ }^{5}$ De alguna manera lo dice Rhodes: "In short, 'good governance' marries the new public management to the advocacy of liberal democracy" (1996: 656).
} 
Los medios masivos de comunicación son claramente uno de ellos, así como los documentos oficiales y, particularmente, las propuestas de los organismos internacionales como el Banco Mundial que, desde los años ochenta, propone agendas urbanas.

En una perspectiva de governance la ciudad no es definida como objeto de disputa, dado que no se pone en cuestión hacia donde se quiere llevar a la ciudad. ${ }^{6}$ En consecuencia, se vuelven poco relevantes las contradicciones y los conflictos, y sus resoluciones con base en posiciones diferenciadas entre los actores que atañen fundamentalmente a la distribución de poder (y de riqueza). La atención se centra, por el contrario, en cómo lograr el mejor camino para la cooperación, desplazando a las otras relaciones que existen en la ciudad.

Como consecuencia, y paradójicamente, se pierde (se desvanece) el componente propiamente político del gobierno de la ciudad; ésta parece ser naturalizada desconociendo su carácter de ámbito político contradictorio de polis.

En la medida que, como dice Rhodes, las redes son entendidas como auto-organizadas y, por lo tanto, autónomas y auto-gobernadas (1996: 659), se dificulta reconocer a la ciudad como trama de relaciones entre actores diferentes, desiguales y contradictorios que tienden a resolver esas diferencias y contradicciones con base en el ejercicio del poder.

Así, el desconocimiento de que "bajo el capitalismo sigue siendo hegemónica la amplia gama de prácticas de clase conectadas a la circulación de capitales, la reproducción de la fuerza de trabajo y las relaciones de clase, y la necesidad de controlar la fuerza de trabajo" (Harvey, 1989: 5) (la traducción es mía) dificulta en extremo percibir a la ciudad como un objeto de relaciones de poder. Para decirlo de manera simplificada, el poder desde el aparato político-burocrático es al que se llega por elecciones; el poder desde el control de las actividades económicas es al que se llega por la propiedad, ${ }^{7}$ mientras el poder desde la sociedad civil es al que se llega con movilizaciones, protestas, participación, etcétera.

\subsection{La orientación como resultado de relaciones de poder}

Partimos del supuesto de que gobernar una ciudad pone fundamentalmente en juego el qué y no sólo el cómo, y se resuelve políticamente con base en relaciones de poder. De esa manera, se trata de la capacidad de

\footnotetext{
${ }^{6}$ Es interesante revisar las definiciones que los planes estratégicos de ciudades han dado para las metas finales desde el primer plan de Barcelona en adelante, pasando por varias ciudades de América Latina: esos objetivos tienen un carácter tan general que no solamente pueden ser compartidos por todos, sino que no garantizan una orientación definida.

${ }^{7}$ Una de esas propiedades es la de los medios masivos de comunicación.
} 
orientar los procesos de configuración y funcionamiento urbanos en el sentido de su significación social, capacidad que si bien tiende a concentrarse en los aparatos estatales, depende de un sistema más amplio de relaciones en el cual entran diferentes redes.

Podemos recordar que, para Polanyi, las decisiones autorreguladas que dejan a las relaciones capitalistas libradas a su fuerza producen resultados desfavorables para la felicidad del individuo y el bienestar general, salvo que "se consiga hacer fracasar las tendencias intrínsecas de las instituciones de mercado", es decir, a partir de una "orientación social consciente que las leyes harán efectiva” (Polanyi, 1997: 213).

Esa orientación social consciente (opuesta a la autorregulación) es resultado de decisiones estatales que se concretan en normas jurídicas (leyes). En sentido contrario, la falta de decisiones que sustentan una orientación consciente implica el predominio de las "tendencias intrínsecas de las instituciones de mercado". Esto último supone el predominio de la "mercantilización universal y hegemónica" en la que "el bienestar de los individuos viene a depender enteramente del circuito monetario" (Esping-Andersen, 1993: 41). Podría decirse que el qué se encuentra estructuralmente tensionado a partir del predominio de la mercantilización.

En consecuencia, podemos mirar la política urbana como el resultado de redes autorreguladas o, por el contrario, a partir de procesos de orientación que se dan con base en las relaciones estructurales y sus tendencias (como la de la mercantilización), pero que introducen modificaciones cuya importancia debe ser identificada históricamente.

Entendemos por orientación la intervención política en el sentido que adoptan los procesos sociales de producción de la ciudad. Esto es, la definición del qué o hacia dónde se intentan conducir esos procesos. Ese qué puede ser entendido como una determinación estructural o como el resultado de relaciones entre actores dentro de limitaciones estructurales. Esto significa que existe una tensión de base estructural hacia la mercantilización de los procesos y productos urbanos, así como tensiones sociales, históricas, en sentidos diferentes.

Por ello es posible identificar, en una ciudad concreta en un tiempo determinado, diferentes metas o diferentes ciudades que podrán resultar de esas intervenciones. Son esas diferencias las que justamente están en juego en la determinación de qué. ${ }^{8}$ La exclusión en el análisis de las posibles disputas por el sentido de esos procesos dificulta o impide captar esas diferencias y heterogeneidades, fortaleciendo la percepción de una realidad urbana sometida a la tensión estructural hacia la mercantilización (Esping-Andersen, 1993) como si ésta fuese el resultado de un proceso

\footnotetext{
${ }^{8}$ El cómo aparecerá subordinado a ese qué.
} 
abierto no jerárquico de toma de decisiones y, a la vez, como algo que supera a las decisiones económicas dentro del mercado.

Aplicada a la ciudad, la orientación es una dimensión de la intervención estatal que depende de tomas de decisiones dentro y fuera de las instituciones gubernamentales y se concreta en la direccionalidad de su producción, distribución y consumo en un doble y opuesto sentido: como bien de uso o, por el contrario, como bien de cambio. Se trata de la posibilidad de tensionar los procesos de producción y funcionamiento urbanos en alguno de esos sentidos.

Decimos orientar en alguno de esos sentidos opuestos, ya que las tensiones estructurales son también actualizadas como orientaciones en la medida que, por lo menos desde mediados del siglo xIx, comenzaron a ser contestadas socialmente, mientras las intervenciones estatales cumplieron el papel de confirmarlas.

Hemos asociado este razonamiento a lo que llamamos la subordinación de la ciudad a la mercantilización que ha sido explicada estructuralmente como una consecuencia de la expansión de las relaciones capitalistas. Así, con la consolidación del capitalismo industrial, no solamente se produce la urbanización de la sociedad, sino que las ciudades se transforman en mercancías: tanto el suelo como otros bienes urbanos (construcciones) se intercambian en el mercado y para acceder a ellos es preciso contar con recursos monetarios que suponen la incorporación en el mercado de fuerza de trabajo. Allí está el origen fundamental de las desigualdades y su correlato territorial. Históricamente, esa situación inicial, la ciudad liberal, ${ }^{9}$ fue modificada en un largo proceso histórico que consistió fundamentalmente en una creciente y contradictoria desmercantilización por medio de la intervención del Estado.

Ese proceso se consolidó con el desarrollo del Estado de Bienestar que, a través de la captación de parte del excedente económico, limitando su acumulación, transfirió en forma directa o indirecta recursos para aquella desmercantilización. Las condiciones particulares tanto económicas como políticas de las sociedades explican las diferencias en esos procesos de desmercantilización de la ciudad (Esping-Andersen, 1993).

Al mismo tiempo, desde mediados de los años setenta del siglo pasado se configura una tendencia contradictoria, ya que se producen cambios críticos en la acumulación capitalista: desindustrialización, expansión del desempleo, austeridad fiscal y presión neoconservadora a favor de la racionalidad del mercado y las privatizaciones, para decirlo con las palabras de Harvey (1989: 5), que sustentan procesos que vuelven a mercantilizar de manera total o parcial diversos componentes (suelo, vivienda, infraes-

${ }^{9}$ Sobre esto puede verse a Munford (1979) y Benevolo (1993). 
tructuras, servicios) como parte de una tendencia de creciente neoliberalización (Harvey, 2005; Theodore et al., 2009).

Al tener en cuenta lo anterior se vuelve evidente que las perspectivas exclusivamente estructurales de estos procesos permiten poco margen para una interpretación de esas transformaciones (Topalov, 1979) tanto en referencia a los procesos de desmercantilización como a sus contrarios. $\mathrm{Si}$, en contraste, adoptamos una perspectiva que, sin desconocer las constricciones estructurales, identifique los procesos sociales y políticos que sustentan las transformaciones es posible articular una explicación más coherente. ${ }^{10} \mathrm{La}$ investigación puede identificar la capacidad de orientar a la ciudad como bien de uso o como bien de cambio. Volvemos a remarcar esa amplia direccionalidad en tanto suponemos que las construcciones estructurales no garantizan el resultado por mucho que la tensión en ese nivel sea hacia la mercantilización.

Esa capacidad supera, por cierto, a las acciones político-burocráticas o gubernamentales. Como dice Harvey:

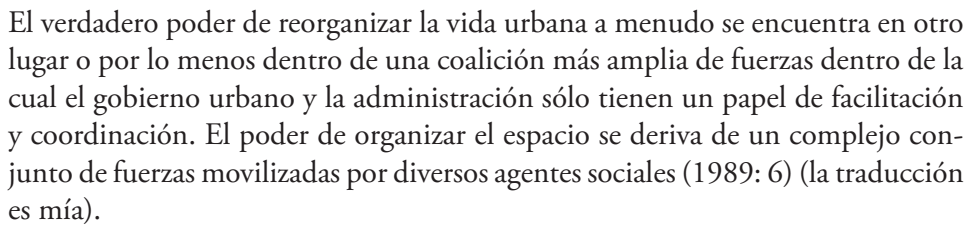

Podríamos aquí hablar de governance en el sentido de que esa capacidad depende del juego de orientaciones político-ideológicas que se sustentan en diferentes situaciones socioeconómicas. De allí que diferenciamos más de un sentido en la capacidad de orientación. ${ }^{11}$ Dicho de otra forma, esa capacidad puede estar referida a diferentes finalidades. Podríamos hablar, en términos históricos, de orientación de crecimiento económico o de distribución, de inclusión o de exclusión.

En consecuencia, es importante para el análisis identificar al gobierno como aparato político-burocrático local: el gobierno municipal. Sin embargo, en pocos casos interviene solamente esa escala gubernamental en el gobierno urbano local, ya que encontramos (con diversos grados y en diferentes asuntos) otras escalas, sean intermedias (provincias o estados en los países federales, o departamentos o regiones en los unitarios) o centrales (nacionales). Esto nos lleva a la necesidad de conocer la trama de las relaciones entre las jurisdicciones presentes en el gobierno urbano y su resolución. Para ello es preciso conocer la estructura gubernamental

\footnotetext{
${ }^{10}$ Podemos pensar en los ensayos de la segunda parte del texto de Offe (1990).

${ }^{11}$ Como es fácil de comprender, el término que utilizamos (capacidad de orientación) puede ser sustituido (formalmente al menos) por el de gobernabilidad.
} 
y las condiciones sobre atribuciones y recursos ya que la interjurisdiccionalidad se articula con base en su distribución formal (institucional).

Es también central identificar la orientación como resultado de la existencia de una particular relación Estado-sociedad civil. Esta particularidad depende de los actores que intervienen, de su peso (relativo económico, social, político) y de los sistemas de articulación asociados con las tensiones propias de los modelos sociales de desarrollo.

La formulación anterior parecería acercarnos al uso de un esquema de análisis tipo máquina del crecimiento urbano (Logan y Molotch, 2007) o de régimen urbano que apunta a identificar las posibles coaliciones entre actores económicos (business) y actores políticos locales para el desenvolvimiento de políticas urbanas de crecimiento (Stone, 1989). Sin embargo, y no entraremos en la discusión de esa perspectiva de análisis ${ }^{12}$ pues creemos que su aplicación a nuestra realidad no resulta fértil por tres argumentos principales: el diferente papel de los gobiernos locales, en especial su limitado rol en relación a las actividades económicas, el crucial papel de los partidos políticos dentro de la vida local, y la presencia de relaciones interjurisdiccionales, en especial el peso del nivel federal tanto en términos metropolitanos como locales (municipales).

De allí que prefiramos proponer un análisis con base en el concepto de sociedad politica entendida como la esfera que combina sociedad civil y Estado como resultado de "complejos sistemas de intermediación y negociación de intereses de diversa naturaleza” en los cuales "toma cuerpo a través de la intensidad y diversidad con la que los actores sociales, individuales y colectivos tratan de hacer valer sus intereses en la toma de decisiones que subyacen a las políticas públicas" (Navarro, 2002).

Esto supone atender a los actores participantes, sus recursos, actitudes, estrategias, relaciones, etcétera. Esas interacciones introducen de manera creciente a corporaciones o asociaciones que, a su vez, articulan intereses particulares y tienden a configurar diferentes modelos de gobernabilidad. Los esquemas ideológicos, por su parte, tienden a justificar el predominio de unos intereses (públicos o privados, por ejemplo).

La sociedad política es así un "sistema de interacción en el que participan actores civiles y gubernamentales [...] un espacio público participativo en el que colisionan, negocian y llegan a acuerdos actores (e intereses) públicos y privados.” Es, por eso, el “ámbito de la movilización, la participación y la representación política”. De allí que se articula fundamentalmente por medio de dos procesos: electoral en el que tienden a predominar recursos de carácter cuantitativo ("el ejercicio del poder depende de la acumulación de apoyos electorales") y corporativo donde

${ }^{12}$ Puede verse Pírez (2007). 
prima "la capacidad de influencia que no se deriva necesariamente del tamaño del grupo sino de su capacidad organizativa, reputación, información que posee y maneja, y más en general, de su situación, su centralidad, en la trama de relaciones que constituye la sociedad política" (Navarro, 2002: pp. 2-4).

Esa trama social depende de cada lugar y de cada momento. Sin embargo, podemos encontrar aparatos estatales correspondientes a las tres escalas y sus diferentes brazos y organizaciones (ejecutivos, legislativos, judiciales) $;^{13}$ organizaciones de clase como las asociaciones de industriales, comerciantes o de bancos; organizaciones obreras; organizaciones de desempleados; empresas o grupos económicos industriales, comerciales o inmobiliarios; partidos políticos (nacionales, regionales o locales); organizaciones sociales de base sectorial y territorial; y organizaciones no gubernamentales.

Las relaciones se organizan en torno a un centro gubernamental. El sentido particular de la orientación que así resulte dependerá de la específica relación que se dé en la sociedad política de que se trate: de qué escalas estatales y aparatos gubernamentales y qué grupos sociales quedan comprometidos. ${ }^{14}$ En otro nivel, dependerá también de la capacidad personal de quienes dirijan tanto los aparatos gubernamentales como los sociales, capacidad que les permitirá encontrar los objetivos que unan las fuerzas y las vías de acción para ejecutar los programas que se basen en esos objetivos.

Esas coaliciones se concretarán en políticas públicas que actualizarán los sentidos de la orientación que promueven. Esas capacidades tenderán a garantizar a los principales integrantes el logro de sus intereses fundamentales: procesos de acumulación, política-electoral, condiciones de localización y rentabilidad, condiciones de sobrevivencia, etcétera.

Una reflexión especial merecen las transformaciones urbanas producidas por los cambios de la reestructuración y globalización, en especial la presencia de nuevos actores y diferentes relaciones de fuerza entre ellos. ${ }^{15}$ Los procesos de privatización de los servicios urbanos han puesto en el centro de las decisiones fuertes capitales de origen predominantemente internacional. La creciente financierización de las economías y en particular de los sectores inmobiliarios también ha incidido.

\footnotetext{
${ }^{13}$ Es creciente la intervención en tal sentido de los aparatos judiciales. Ver Azuela y Cosacov (2013).

${ }^{14}$ Uno de los pocos ejemplos en ese sentido en la Argentina actual es la legislación de ordenamiento territorial de la provincia de Mendoza, y su aplicación al Área Metropolitana de la ciudad de Mendoza (Ver Marina-Berón et al. 2013).

${ }^{15}$ Puede ser útil el análisis de esos procesos en una ciudad argentina intermedia para tener una referencia respecto del territorio urbano que se focaliza en este trabajo. Ver Bergesio y Golovanevsky, (2014).
} 
Además, junto con los organismos internacionales de crédito (e influencia política) (BID, BM, FMI), puede percibirse la presencia de gobiernos extranjeros que presionan tanto a favor de sus empresas como de ciertas orientaciones de políticas, muchas veces asociadas a las condiciones de la deuda externa de los países.

También son relevantes las discontinuidades espaciales metropolitanas, la creciente fragmentación de sus diferentes territorios así como el aumento de las condiciones de segregación de la población y la ampliación de las distancias sociales (desigualdades). En algunos casos esas distancias se dan en proximidades físicas que caracterizan situaciones de microfragmentación (Pírez, 2006).

Dentro de esa trama compleja se produce una diferenciación en lo que podemos llamar la división del trabajo estatal: el nivel federal vinculado predominantemente con los actores económicos y el local con las cuestiones relativas a la reproducción de la población y especialmente la de menores recursos; a su vez, el nivel intermedio (provincial-estadual) se relaciona con ambos.

\section{La orientación de la gobernabilidad metropolitana en Buenos Aires $^{16}$}

Como hemos dicho, esta reflexión surge de los trabajos sobre la realidad metropolitana de Buenos Aires, en particular de los cambios que se impusieron como parte del proceso de reestructuración neoliberal, fundamentalmente durante los años noventa del siglo xx. Para ello atendemos a la estructura gubernamental presente en ese territorio metropolitano y a la estructuración de las relaciones políticas que permiten analizar las decisiones como parte de procesos de orientación.

\subsection{Las condiciones del aparato político-burocrático}

El Área Metropolitana de Buenos Aires es un territorio políticamente fragmentado sin un gobierno metropolitano, donde se ha desarrollado un proceso de centralización jurisdiccional por medio del cual algunas cuestiones metropolitanas han sido asumidas por la jurisdicción superior. Este es el gobierno federal, en referencia a la relación entre la provincia y la ciudad de Buenos Aires, y el gobierno provincial en el área territorial que le corresponde, respecto de los municipios que la integran. Esas re-

\footnotetext{
${ }^{16}$ Nos referimos tanto al Área Metropolitana de Buenos Aires (integrada por la ciudad de Buenos Aires y 24 municipios de la provincia de Buenos Aires conurbados con aquélla) como a la Región Metropolitana de Buenos Aires que integra además otros 10 municipios al Área Metropolitana de La Plata.
} 
laciones se definen institucionalmente en razón de las atribuciones de cada una de esas escalas gubernamentales y particularmente de los recursos que ellas controlan.

El resultado es una suerte de pirámide en cuyo vértice se encuentra el gobierno federal (Pírez, 1994 y 2001); junto a esa estructura institucional encontramos procesos de acumulación política electoral de los que depende el acceso a las posiciones de toma de decisión en cada una de las escalas estatales (local, provincial y federal). Esos procesos están recortados territorialmente, corresponden con dichas escalas y se ordenan en tres circuitos diferenciados.

La consecuencia de esto es la consolidación de un sistema jerárquico con el gobierno federal como cúspide de una situación piramidal; en la medida que los vínculos interjurisdiccionales se canalizan por medio de partidos políticos es relevante la diferente definición partidaria de esos gobiernos. La pertenencia al mismo partido suele significar una garantía para la fluidez de las relaciones, aunque si se trata de miembros de facciones enfrentadas dentro del mismo partido el resultado puede ser negativo (Pírez, 2008).

En esa estructura piramidal, los municipios ocupan la base, en una posición intermedia está el gobierno provincial y en la cúspide el gobierno federal. El gobierno de la ciudad de Buenos Aires ocupa una posición análoga a la del gobierno provincial, en situación de mayor autonomía relativa frente al gobierno federal. La ciudad de Buenos Aires y los municipios metropolitanos forman parte de dos universos políticos diferentes cuyos procesos fundamentales cortan la realidad metropolitana, dificultando percibir su unidad real. El gobierno de la ciudad de Buenos Aires y el provincial forman parte de un mismo universo político dada su relativa paridad (provincial) ${ }^{17}$ y su vinculación con el gobierno federal.

La posible cooperación entre el gobierno de la ciudad de Buenos Aires y el provincial se ve limitada por sus relaciones con el gobierno federal: el territorio metropolitano es parte del ámbito de acumulación electoral del gobierno federal, ${ }^{18}$ por lo que sus intervenciones pueden recuperar la unidad metropolitana; el segmento provincial metropolitano forma parte del ámbito de acumulación del gobierno provincial, y sus intervenciones pueden recuperar la unidad metropolitana de ese territorio parcial. La acumulación política (electoral) promueve la competencia entre los actores participantes en relaciones de suma cero; las solidaridades objeti-

\footnotetext{
${ }^{17}$ Si bien la ciudad de Buenos Aires no es institucionalmente una provincia, su definición constitucional y su constitución local definen una entidad sumamente análoga a la provincial.

${ }^{18}$ Recordemos que la Región Metropolitana contiene una tercera parte de los votos que eligen al presidente y vicepresidente.
} 
vas entre el gobierno de la ciudad y el de la provincia están condicionadas por la posibilidad de veto del gobierno federal (Pírez, 2008).

\subsection{Política metropolitana y orientación de la ciudad}

Las decisiones de orientación pueden analizarse a partir de la base institucional de la estructura político-gubernamental que las produce y en razón de las relaciones que desde esa base se estructuran. Para analizar esos fenómenos, atendemos a la realidad metropolitana durante la aplicación de políticas de restructuración neoliberal como parte de un proceso de inclusión en las relaciones globalizadas. Para este fin partimos de cuatro supuestos que permiten organizar el análisis. El papel del Estado es central en la configuración de las transformaciones que se dan en la realidad económica y social metropolitana y, como consecuencia, en sus cambios territoriales. En ese sentido, el gobierno federal asume un rol fundamental.

El comportamiento del gobierno federal se relaciona con los procesos de acumulación política que se determinan en el ámbito nacional. Sus bases son la capacidad territorial de control de los votos en provincias y municipios, y las relaciones dentro del partido gobernante, con sus expresiones territoriales y el peso relativo de sus líderes. En consecuencia, es diferente la significación de los distintos territorios particulares (provincias o municipios), en razón del lugar que ocupan o pueden ocupar en las estrategias de acumulación electoral.

Asimismo, la sociedad política metropolitana (SPM) se configura en torno del gobierno federal (cúspide de la pirámide intergubernamental metropolitana) y está integrada por los principales grupos económicos, con sus empresas y organizaciones corporativas, articulando el poder económico nacional. ${ }^{19} \mathrm{El}$ territorio metropolitano pone también en vinculación al gobierno federal con las organizaciones populares de base que tienden a ser controladas desde los gobiernos municipales. ${ }^{20}$ Las políticas federales para la metrópoli se definirían, entonces, en ese sistema de relaciones de la SPM, refiriéndose de manera preferente a los intereses económicos mencionados. ${ }^{21}$

Suponemos, en tercer lugar, que las decisiones del gobierno federal, en esa SPM, dependen de sus "preferencias de política económica, es decir, [...] preferencias acerca de cómo organizar y manejar la economía del

\footnotetext{
${ }^{19}$ Se identifican en el próximo apartado.

${ }^{20}$ Se trata de los grupos organizados territorialmente a partir de la desafiliación generada por el desempleo y que reciben recursos de origen federal a través de los gobiernos municipales que tienden a introducirlos en relaciones clientelares. Grupos conocidos como piqueteros (Merklen, 2005).

${ }^{21}$ Este supuesto que pudiera ser planteado en general, se refiere de manera particular a las condiciones políticas de gobernabilidad en esos años que, como veremos, le otorgaban un papel decisivo a los actores económicos concentrados.
} 
país" 22 (Bonvecchi, 2002: 110) y de la finalidad de maximizar los resultados electorales en el proceso de acumulación política.

La definición de las preferencias se asocia con la acumulación política, en el sentido de que el proyecto que se asume y se propone es el que, de acuerdo a las valoraciones de los políticos, podrá maximizar los resultados electorales. Priman las preferencias de politica económica y

los gobiernos diseñan sus políticas económicas en función de criterios acerca de la organización y el manejo de la economía, y que es sobre la base de estos criterios que elaboran las estrategias políticas para su implementación [...] (incluyendo) el cálculo de los costos de transacción [...] Calculados esos costos, los gobiernos definen una serie de jugadas tácticas orientadas a lograr el objetivo de encauzar el funcionamiento económico [...] Esta serie de jugadas conforma la estrategia de la política económica que en su prosecución se encuentra con las estrategias de diversos actores económicos y políticos (Bonvecchi, 2002: 111), (las itálicas son mías).

La concreción de esos costos de transacción nos permite proponer un cuarto supuesto: las decisiones tendrán en cuenta las condiciones que permiten poder gobernar, mantenerse en el gobierno e implementar sus preferencias. Esas condiciones dependen de los resultados del encuentro con las estrategias de los otros actores, particularmente, económicos. Este encuentro podrá ser la base de coaliciones de diferente significación y grado, particularmente por parte de los que podemos llamar los poderes corporativos, en especial los económicos.

\subsection{Los procesos metropolitanos en Buenos Aires}

Los años ochenta terminaron en Argentina con una fuerte crisis. En el primer semestre de 1989 la hiperinflación ${ }^{23}$ y la fuga de divisas permitieron hablar del "golpe económico más importante desde el retorno de la democracia” (Rapoport, 2005: 752). En julio, el presidente Alfonsín entregó el gobierno con seis meses de anticipación. Durante la campaña electoral, Carlos Menem, que resultara electo presidente, había hecho explícitas sus preferencias con una definición de desarrollo del mercado interno (revolución productiva) y fuerte redistribución (salariazo).

En esos meses se evidenció el poder de los grupos económicos que habían logrado torcer la voluntad del gobierno elegido en 1983, obligándolo a retirarse anticipadamente. Poco antes de que Menem asumiera el

\footnotetext{
${ }^{22}$ Esto hace referencia a una formulación particular de lo que consideramos la orientación propia de las políticas estatales.

${ }^{23}$ Entre febrero y agosto de 1989 el tipo de cambio aumentó $3639.70 \%$ y el costo de vida $2576.90 \%$ mientras que los salarios reales cayeron $30.10 \%$ (Rapoport, 2005).
} 
poder se recrudeció la inflación: en julio los precios subieron 197\% y las tarifas de los servicios de redes $700 \%{ }^{24}$ (Rapoport, 2005).

La crisis mostró el peso de dos actores económicos: los acreedores externos y los grupos concentrados internos (Basualdo, 2002; Rapoport 2005). La moratoria del pago de la deuda externa privada de 1988 habría detonado la corrida contra el peso, a cargo en especial de la banca extranjera y el desencadenamiento de la hiperinflación.

Entonces se generaban las bases para resolver la contradicción entre la acumulación interna de capitales concentrados y los acreedores externos, en la medida que la crisis sesgaba hacia salidas que cargarían sobre los asalariados (continuidad de la disminución del salario real, desocupación y precarización) y sobre el Estado, que transferiría no solamente parte de su captación sobre el excedente, sino en particular el patrimonio social acumulado (Basualdo, 2002).

Esto permitiría articular los intereses de esos dos grupos que, pese a la complejidad de sus relaciones, coincidían en que la superación de la crisis debía "acentuar la concentración del ingreso y encarar la privatización de las empresas públicas". Para los acreedores externos esto era una manera de recuperar, por la capitalización de sus bonos, una parte del capital que se les adeudaba. Para el capital concentrado interno era la posibilidad de acceder a la propiedad de activos de gran magnitud con elevada rentabilidad potencial (Basualdo, 2002: 50).

La crisis evidenció la debilidad del gobierno para garantizar la continuidad del proceso de acumulación, reduciendo sus opciones. El nuevo presidente dejó de lado las preferencias anunciadas, se apoyó en los actores económicos predominantes y redefinió la estrategia, adecuándola a sus intereses, con un

programa de reformas estructurales que parecía proveer los tres pilares necesarios para tender un puente que permitiera huir de la crisis fiscal: concitar el apoyo del mundo de los negocios, ser el camino más apropiado hacia un entendimiento con los organismos internacionales de crédito y los bancos acreedores, y dar una respuesta al difuso 'consenso de terminación' perceptible en la opinión pública (Palermo y Novaro, 1996: 129).

El gobierno parecía convencido "de que su capacidad para implementar políticas sin contar con la anuencia de los actores económicos predominantes era prácticamente nula" (Palermo y Novaro, 1996: 130). Para ello, el presidente apuntó, con un claro pragmatismo, a "la conformación de una coalición entre un gobierno que disponía de un fuerte respaldo

\footnotetext{
${ }^{24}$ Como consecuencia de la hiperinflación la deuda pública aumentó $60 \%$ entre febrero y junio, al tiempo que los ingresos de tesorería se reducían violentamente en términos reales.
} 
popular y quienes se suponían podían controlar las variables económicas” (Palermo y Novaro, 1996: 131).

El debilitamiento del gobierno era necesario para definir la salida de la crisis; el apoyo de los grupos económicos que la habían generado aparecía, para la nueva mirada gubernamental, como la base de la gobernabilidad. De allí la relevancia de consolidar esa coalición con la participación en el gabinete de miembros de las grandes empresas ${ }^{25}$ y dirigentes políticos de partidos de derecha, ${ }^{26}$ así como la definición de un claro cambio de rumbo.

El gobierno federal consolidó una coalición nacional (de la que formó parte una coalición metropolitana), ya que para entonces "se había articulado una sólida comunidad de intereses entre los grupos económicos locales ${ }^{27}$ y extranjeros ${ }^{28}$ que conformaban la cúpula empresarial histórica de la Argentina, los grandes bancos acreedores propietarios de títulos de la deuda y los nuevos operadores extranjeros de los servicios privatizados" (Rapoport, 2005: 899).

El cambio de preferencias, que está en la base de esa coalición, podía ser cuestionado por ciertas fracciones del partido gobernante y por las organizaciones sindicales ${ }^{29}$ que eran parte del mismo. Pero el gobierno logró controlar y cooptar a los dirigentes políticos ${ }^{30}$ y sindicales $^{31}$ (Palermo y Novaro, 1996; Rapoport, 2005).

La nueva orientación implicó la reforma del Estado y de la economía: disminución del aparato estatal y modificación de una orientación de bienestar hacia la re-mercantilización de varios ámbitos importantes para la población, tal como la seguridad social, la salud, la educación y las condiciones urbanas de vida.

${ }^{25}$ Los primeros ministros de economía fueron funcionarios de la transnacional argentina Bunge $\&$ Born.

${ }^{26}$ Provenientes de la UCeDe, como Álvaro Alsogaray y su hija María Julia, entre otros.

${ }^{27}$ Entre ellos los grupos Perez Companc, Macri-socma, Roggio, Soldati, Loma Negra y otros.

${ }^{28}$ Entre otros, el CEI Citicorp Holding, el grupo EXXel, Techint y Bemberg.

${ }^{29}$ Los sindicatos no tuvieron una posición uniforme: algunos apoyaron inicialmente las reformas y privatizaciones, como los empleados de comercio (Cavalieri), plástico (Triaca), taxistas (García) y automotriz (Rodríguez), buscando conseguir o recrear posiciones de poder; otros como la uOM de Miguel, se propusieron oponerse para negociar; por último, algunos se opusieron frontalmente, excluyéndose de toda negociación, como la CGT de Azopardo, el MTA (Moyano) entre otros y, dentro de un sector particular, los empleados telefónicos. (Palermo y Novaro, 1996). Entre los sindicatos que se plegaron a las reformas puede mencionarse a los trabajadores eléctricos de Luz y Fuerza, que terminaron como empresarios asociados a las empresas privatizadas, o los de la empresa de agua y saneamiento que se incorporaron a los aparatos de regulación de la privatización.

${ }^{30}$ Menem enfrentó las presiones de los gobernadores forzándolos a firmar el primer Pacto federal (mayo de 1990), advirtiendo que la crisis y sus propias necesidades podrían dar lugar a un nuevo espacio partidario, dado su acercamiento a los liberales y a fuerzas provinciales de centro-derecha, con las que propuso formar una Liga de Ganadores para 1991 (Palermo y Novaro, 1996).

${ }^{31}$ Se programó una participación de los empleados en $10 \%$ del capital de las empresas privatizadas. Sin embargo, nunca se concretó en capacidad de control. 
Dado el peso del gobierno federal, esa orientación afectó claramente la configuración de las relaciones políticas, sociales y económicas del territorio metropolitano.

La privatización de los servicios de infraestructura que estructuran el territorio metropolitano (agua y saneamiento, electricidad, gas natural, teléfonos, ferrocarriles, trenes subterráneos, accesos viales) fue decidida por razones de naturaleza macro-económica y político-nacional (Gerchunoff, 1992), es decir, como parte de la nueva orientación que correspondía a la coalición conformada.

La nueva regulación permitió que las empresas privatizadas y los grupos económicos asociados a ellas obtuvieran ganancias extraordinarias (Azpiazu, 1997), subordinando las condiciones de operación, competitividad y rentabilidad del resto de las actividades económicas y, particularmente, las necesidades de la población de bajos recursos.

Fueron ignoradas las condiciones de los territorios y los servicios se definieron como relaciones privado-mercantiles; en el mismo sentido operaron las privatizaciones de los accesos a la ciudad de Buenos Aires en las principales redes viales metropolitanas, el puerto y los aeropuertos. En todos ellos, esas empresas, infraestructuras y servicios metropolitanos se regularon y controlaron de manera sectorial. Se atendieron los intereses de los sectores considerados claves en un sentido macroeconómico, sin atender a las condiciones económicas de la unidad metropolitana. Las políticas aplicadas en la ciudad de Buenos Aires ${ }^{32}$ también apoyaron esta interpretación (privatizaciones generalizadas de servicios municipales).

Esas decisiones del gobierno federal afectaron al territorio metropolitano y a sus gobiernos locales, que debieron enfrentar los conflictos suscitados. La coalición metropolitana integró a quienes aprovecharon los efectos de la transformación de las infraestructuras, fundamentalmente capitales inmobiliarios y financieros (con importante peso externo) y clases medias altas que, beneficiadas con las nuevas fuentes de empleo en el sector terciario de alta remuneración, se basaron en esa modernización urbana para mejorar sus condiciones de asentamiento. Esta coalición era un componente fundamental de la coalición política nacional, dada la localización en el territorio metropolitano de la mayor parte de los grupos económicos nacionales (o sus conducciones) y la residencia de sus directivos y empleados superiores.

Los resultados fueron la privatización de la producción urbana metropolitana, el incremento de la fragmentación, y el deterioro de las condiciones de producción, en particular de las empresas medianas y pequeñas

\footnotetext{
${ }^{32}$ Recordemos que hasta 1996 el ejecutivo local depende del presidente.
} 
y de las condiciones de vida de los grupos de menores ingresos (Ciccolella, 2009; Pírez, 2006; Torres, 2001).

\section{Conclusiones}

Los estudios sobre la realidad metropolitana, tanto en Argentina como en el resto de América Latina, han desarrollado discursos predominantemente normativos, buscando identificar las formas político-institucionales necesarias para su gobierno y gestión. El esfuerzo destinado a conocer las condiciones políticas actuales de esos territorios ha sido limitado; es probable que una de las razones de ello sea la pobre conceptualización de lo metropolitano como unidad de relaciones políticas que permite superar el encierro del análisis dentro de las escalas territoriales del estado (nacional, provincial o intermedio y municipal o local). Esto, por su parte, se relacionaría con el limitado trabajo teórico que pueda sustentar otro tipo de estudios.

La evolución de las interpretaciones de governance aportó un esquema que parecía permitir superar las limitaciones que mencionamos. Sin embargo, la reflexión sobre esas perspectivas, en referencia a la realidad metropolitana que estudiamos, muestra una serie de limitaciones que parecen distraer la atención de un núcleo conceptual de mayor potencial explicativo para la investigación.

De acuerdo con los estudios que sustentan esta reflexión, los riesgos de desdibujar el papel estatal y a la vez promover una mirada que dificulta percibir las desigualdades de la distribución del poder, particularmente su concentración, limitan la fecundidad explicativa de esas perspectivas. Por otra parte, los análisis de gobernabilidad urbana tienden a focalizarse en las dimensiones instrumentales dejando fuera los objetivos o metas de las decisiones políticas. Esto último, ciertamente, es coherente con la supuesta homogeneidad dentro de los actores y, particularmente, entre redes autorreguladas.

Hemos intentado superar esa perspectiva introduciendo la noción de orientación como intervención política que define el sentido que adoptan los procesos de producción de la ciudad. Esa intervención se concreta en decisiones gubernamentales y se basa en relaciones que se dan en la sociedad política.

De esta manera, es posible recuperar la centralidad estatal y la trama de relaciones desiguales entre diversos actores de la sociedad, así como entre ellos y los aparatos estatales. Es posible, también, ampliar las relaciones que se dan entre los aparatos gubernamentales, particularmente en sus diferentes escalas (relaciones interjurisdiccionales). 
La reflexión teórica fue parte de los estudios sobre la realidad metropolitana de Buenos Aires; de allí que en este artículo presentamos, sucintamente, un intento de interpretación de un momento particular. Para ello hicimos una descripción de las condiciones de la política metropolitana en los ańos noventa del siglo $\mathrm{xx}$, apuntando a interpretar las transformaciones que se produjeron e impactaron en el territorio, condiciones críticas por la limitación de alternativas debidas al debilitamiento estatal y a la concentración económica, y que obligaron a decidir sobre la continuidad o ruptura de las definiciones políticas básicas.

Así, la noción de orientación de los procesos sociales aparece como parte de políticas estatales que resultan de procesos de concentración de poder y que producen importantes modificaciones en la configuración y el funcionamiento metropolitanos.

Las políticas implementadas a comienzos de los años noventa del siglo $\mathrm{xx}$ fueron decisiones que modificaron de manera radical las preferencias de políticas anunciadas previamente. El contexto de ese cambio resultó, por una parte, de la debilidad estatal provocada por la pesada deuda externa ${ }^{33}$ y de los frustrados intentos de operar hacia una estrategia económica que dejara márgenes para la acumulación local. ${ }^{34}$

Frente a eso, el llamado golpe económico de 1989 desestructuró las relaciones económicas, obligando a adelantar la entrega del gobierno de parte del presidente Alfonsín y condicionó claramente la toma de decisiones. En ese momento el nuevo gobierno dio un giro en el sentido de una orientación claramente neoliberal. Ante los intentos de mantener condiciones de redistribución, la política se orientó a la recuperación para el capital de los bienes sociales acumulados y a la destrucción de la protección del trabajo consolidada durante el periodo desarrollista.

Esa opción fue la condición del apoyo económico y político de la coalición entre acreedores externos y grupos concentrados nacionales.

El lugar fundamental de afectación de la reestructuración fue el territorio metropolitano debido a la particular presencia federal en el área (centralización jurisdiccional) y sus condiciones históricas, particularmente por la presencia de las empresas estatizadas cuarenta o cincuenta años antes.

El análisis sugiere la relevancia del papel estatal y, particularmente, del nivel central o federal en la producción de políticas que orientan el territorio metropolitano. Es posible pensar en la existencia de una suerte de gobierno jurisdiccionalmente compartido, con base en procesos de centralización jurisdiccional, y en un claro predominio en esas relaciones del nivel

\footnotetext{
${ }^{33}$ En 1989 era de 65,300 millones de dólares.

${ }^{34}$ Un buen indicador fue la mencionada hiperinflación de 1989 y 1990.
} 
federal. De tal manera, resulta una cierta unidad de decisiones políticas para buena parte del territorio metropolitano en algunos sectores fundamentales para la orientación de los procesos urbanos. ${ }^{35}$ Puede ser interpretado como una unidad de orientación de los procesos metropolitanos.

Ese análisis permite vincular la centralización jurisdiccional con las orientaciones políticas del nivel federal y, particularmente, con los actores fundamentales, principal pero no exclusivamente, económicos, que están por detrás de ellas. En consecuencia, esas decisiones (o políticas) metropolitanas se asocian al desarrollo de una agenda global (no metropolitana) que toma en cuenta los intereses de los grupos económicos predominantes a escala nacional y su presencia en el territorio metropolitano (sociedad política metropolitana).

El periodo analizado puede ser entendido como la continuación de la configuración metropolitana que fue consecuencia de las infraestructuras desarrolladas luego de su estatización y centralización entre los años cuarenta y cincuenta del siglo xx, junto con las acciones de la población que migraba y debía resolver por sí misma las condiciones de su asentamiento, tanto en lo que se refiere al suelo como a la vivienda. Resolver por medio de procesos institucionales, como el mercado de loteos populares o por medio de procesos informales, como las villas miseria y los asentamientos (Clichevsky, 1990; Pírez, 2009; Torres, 2006).

En el periodo en el que centramos el análisis, la intervención del gobierno federal imprimió una particular orientación en la configuración metropolitana (ampliación de la segregación por producción de urbanizaciones cerradas para población de altos recursos y ocupaciones -asentamientos- de la población de bajos recursos, fortaleciendo las tradicionales desigualdades norte/sur y centro/periferia) y en su funcionamiento (dificultad de la población de bajos recursos para ingresar y mantenerse en los servicios a la vez que sobre-ganancias empresarias con su gestión).

Los intereses y necesidades de los grupos de menores recursos quedaron subordinados; fue difícil obtener los elementos urbanos de su reproducción (suelo, vivienda, servicios) dada la mercantilización de los procesos de configuración y funcionamiento de ese territorio.

Al mismo tiempo, la creciente importancia de la población excluida de las condiciones mercantiles de acceso a la ciudad se concretó en la formación de procesos sociales de desmercantilización en la producción de una ciudad informal. Las dificultades de inclusión en la resolución del mercado, consecuencia de los procesos de gobierno urbano con predo-

${ }^{35}$ De allí que el gobierno federal haya sido entendido como "gobierno metropolitano" (Pírez y Labanca, 2009). 
minio de orientación mercantil de la producción urbana, se enfrentó de manera desmercantilizadora desde fuera del Estado.

\section{Bibliografía}

Arantes, Otília, Carlos Vainer y Ermínia Maricato (2000), A cidade do pensamento único. Desmanchando consensos, Editora Vozes, Petrópolis.

Arbós, Xavier y Salvador Giner (1993), La gobernabilidad, ciudadania y democracia en la encrucijada mundial, Siglo XXI, Madrid.

Azpiazu, Daniel (1997), "El nuevo perfil de la elite empresaria. Concentración del poder económico y beneficios extraordinarios", Realidad Económica, núm. 145, IDAE, Buenos Aires, pp. 7-32.

Azuela, Antonio y Natalia Cosacov (2013) "Transformaciones urbanas y reivindicaciones ambientales. En torno a la productividad social del conflicto por la construcción de edificios en la Ciudad de Buenos Aires”, EURE, 39 (118), Universidad Católica de Santiago, pp 149-172.

Basualdo, Eduardo (2002), Concentración y centralización del capital en la Argentina durante la década del noventa, Universidad Nacional de Quilmes-Flacso-IDEP, Buenos Aires.

Benevolo, Leonardo (1993), La ciudad europea, Crítica, Barcelona.

Bergesio, Liliana y Laura Golovanevsky (2014), "Las ciudades y sus muros de cristal. Ajuste neoliberal en una experiencia del noroeste argentino", Economía, Sociedady Territorio, XIV (44), El Colegio Mexiquense, A.c., Zinacantepec, pp. 1-48.

Bonvecchi, Alejandro (2002), "Estrategia de supervivencia y tácticas de disuasión. Los procesos políticos de la política económica después de las reformas estructurales", en Marcos Novaro (comp.), El derrumbe politico en el ocaso de la convertibilidad, Norma, Buenos Aires, pp. 107-193.

Ciccolella, Pablo (2009), "La metrópolis post social: Buenos Aires, ciudadrehén de la economía global", en Pedro Pírez (ed.), Buenos Aires, la larga formación del presente, Olacchi, Quito, pp. 35-62. 
Clichevsky, Nora (1990), "Política urbana y sector inmobiliario", en Nora Clichevsky, Marie France Prevot-Schapira y Graciela Schneier, Loteos populares, sector inmobiliario y gestión local en Buenos Aires, Cuadernos del ceur, Buenos Aires, pp. 3-82.

Crozier, Michel, Samuel Huntington y Joji Watanuki (1975), The crisis of democracy. Report on the governability of democracies to the trilateral commission, New York University Press, New York.

Davis, Jonathan (2011), "Repensando las redes, gobernanza como hegemonia”, en Mario Bassols y Cristóbal Mendoza (coords.), Gobernanza. Teoría y práctica colectivas, Anthropos, Barcelona, pp. 35-65.

Esping-Andersen, Gosta (1993), Los tres mundos del Estado del Bienestar, Edicions Alfons El Magnanim-Generalitat Valenciana, Valencia.

Gerchunoff, Pablo (ed.) (1992), Las privatizaciones en la Argentina, Instituto Torcuato Di Tella, Buenos Aires.

Jouve, Bernard y Christian Lefèvre (2004), “¿La nueva edad de oro de las ciudades europeas?”, en Bernard Jouve y Christian Lefèvre (dirs.), Metrópolis ingobernables. Las ciudades europeas entre la globalización y la descentralización, Ministerio de Administraciones Públicas, Madrid, pp. 9-32.

Harvey, David (1989), "From managerialism to entrepreneurialism: the transformation in urban governance in late capitalism”, Geografiska Annaler, 71 (1), Wiley-Swedish Society for Anthropology and Geography, Stockholm, pp. 3-17.

Harvey, David (2005), A brief history of neoliberalism, Oxford University Press, Oxford-New York.

Landau, Matías (2008), Política y participación ciudadana, Miño y Dávila, Buenos Aires.

Logan, John y Harvey Molotch (2007), Urban fortunes. The political economy of place, University of California Press, Berkeley-Los Ángeles. 
Marina, Berón, Nélida, Cristian Harry Padilla-Rodríguez y Nadia Rapali (2013), "Nuevo marco normativo de Ordenamiento Territorial en Mendoza: su aplicación en el Área Metropolitana”, Bitácora, 22, Universidad Nacional de Colombia, Bogotá, pp. 97-108.

Merklen, Denis (2005), Pobres ciudadanos. Las clases populares en la era democrática (Argentina, 1983-2003), Gorla, Buenos Aires.

Munford, Lewis (1979), La ciudad en la historia, Infinito, Buenos Aires.

Navarro, Clemente (2002), "La sociedad política como agenda de investigación: delimitación conceptual y marcos analíticos” ponencia presentada en el VII Congreso Internacional del CLAD sobre la Reforma del Estado y de la Administración Pública, 8-11 de octubre, Lisboa.

Offe, Claus (1990), Contradicciones en el estado de bienestar, Alianza, Madrid.

Palermo, Vicente y Marcos Novaro (1996), Politica y poder en el gobierno de Menem, Norma, Buenos Aires.

Pírez, Pedro (1994), Buenos Aires metropolitana. Politica y gestión de la ciudad, Centro Editor de América Latina, Buenos Aires.

Pírez, Pedro (2001), "Cuestión metropolitana y gobernabilidad urbana en la Argentina”, en Antonio Vázquez Barquero y Óscar Madoery (comps.), Transformaciones globales, instituciones y politicas de desarrollo local, Homo Sapiens Ediciones, Rosario, pp. 257-286.

Pírez, Pedro (2006), "La privatización de la expansión metropolitana en Buenos Aires", Economí, Sociedady Territorio, VI (21), El Colegio Mexiquense, A.C., Zinacantepec, pp. 31-54.

Pírez, Pedro (2007), "Para (re) pensar la gestión metropolitana (con sesgo político)”, en Territorios Metropolitanos, núm. 1, Universidad Autónoma Metropolitana, México, pp. 7-24.

Pírez, Pedro (2008), "Gobernanza metropolitana, centralización jurisdiccional y relaciones políticas”, en Gloria Yañez, Arturo Orellana, Óscar Figueroa y Federico Arenas (eds.), Ciudad, poder, gober- 
nanza, Instituto de Estudios Urbanos y Territoriales-Pontificia Universidad Católica de Chile, Santiago de Chile, pp. 91-115.

Pírez, Pedro (2009), Las sombras de la luz. Distribución eléctrica, configuración urbana y pobreza en la Región Metropolitana de Buenos Aires, Eudeba, Buenos Aires.

Pírez, Pedro y Facundo Labanca, (2009), "La ciudad metropolitana de Buenos Aires tiene gobierno”, Revista de Ciencias Sociales, núm. 16, Universidad Nacional de Quilmes, Bernal, pp. 217-232.

Pírez, Pedro (2011), "Distribución eléctrica y desigualdades en la urbanización en América Latina”, ponencia presentada en el Seminario Internacional Infraestructuras Urbanas en América Latina: Gestión y Construcción de Servicios y Obra Pública, Flacso, 6-7 de octubre, Quito.

Polanyi, Karl (1997), La gran transformación. Crítica del liberalismo económico, Ediciones de La Piqueta, Madrid.

Rapoport, Mario (2005), Historia económica, politica y social de la Argentina (1880-2003), Emecé, Buenos Aires.

Rhodes, Rod (1996), "The new governance: governing without government", Political Studies, XLIV (4), Wiley, Hoboken, pp. 652-667.

Stone, Clarence Nathan (1989), Urban regime politics: governing Atlanta 1946-1988, University Press of Kansas, Lawrence.

Theodore, Nik, Jamie Peck y Neil Brenner (2009), "Urbanismo neoliberal: la ciudad y el imperio de los mercados", Temas Sociales, núm. 66, sur-Corporación de Estudios Sociales y Educación, Santiago de Chile, p. 1-11.

Topalov, Christian (1979), La urbanización capitalista, Edicol, México.

Torres, Horacio (2001), "Cambios socioterritoriales en Buenos Aires durante la década de 1990", EURE-Revista Latinoamericana de Estudios Urbano Regionales, 27 (80), Pontificia Universidad Católica de Chile, Santiago, pp. 33-56. 
Torres, Horacio (2006), "El mapa social de Buenos Aires (1940-1990)", Serie Difusión, núm. 3, Universidad de Buenos Aires, Buenos Aires, pp. 1-50.

Recibido: 19 de agosto de 2010. Reenviado: 10 de septiembre de 2012. Aceptado: 14 de noviembre de 2012.

Pedro Pírez. Es doctor en derecho y ciencias sociales por la Universidad Nacional de Córdoba, Argentina. Actualmente es investigador principal del Consejo Nacional de Investigaciones Científicas y Técnicas (Conicet) en el Instituto de Estudios de América Latina y el Caribe de la Facultad de Ciencias Sociales de la Universidad de Buenos Aires. Es profesor en el doctorado en ciencias sociales de la Universidad de Buenos Aires y en la maestría en economía urbana de la Universidad Torcuato Di Tella. Su línea actual de investigación es la problemática metropolitana y los servicios urbanos. Entre sus últimos trabajos se encuentran (ed.) Buenos Aires, la formación del presente, Olacchi, Quito (2009); Las sombras de la luz. Distribución eléctrica, configuración urbana y pobreza en la Región Metropolitana de Buenos Aires, Eudeba, Buenos Aires (2009); "Dos siglos de difícil gobierno", en Alfredo Lattes (coord.), Dinámica de una ciudad. Buenos Aires, 1810-2010, Dirección General de Estadísticas y Censos, Buenos Aires, pp. 389-417 (2010); "Para pensar el gobierno metropolitano de Buenos Aires", en Antonio Cicioni (comp.), La gran Buenos Aires. Rompecabezas metropolitano, Konrad Adenauer-Stiftung-Cippec-Fundación Metropolitana, Buenos Aires, pp. 243-265 (2010); "Gobernabilidad metropolitana o la orientación de los procesos urbanos de la metrópoli de Buenos Aires", en Mario Bassols y Cristóbal Mendoza (coords.), Gobernanza. Teoría y prácticas colectivas, Anthropos, Barcelona, pp. 97-140 (2011); "La urbanización y la política de los servicios urbanos en América Latina", Andamios. Revista de Investigación Social, 10 (22), Universidad Autónoma de la Ciudad de México, México, pp. 45-67 (2013). 